Scientiæ studia, São Paulo, v. 12, n. 2, p. 261-84, 2014

\title{
st \\ Política y vida animal: la analogía del buen gobierno
}

Hernán NEIRA

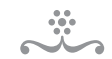

RESUMEN

Aristóteles sostiene que los animales no requieren un monarcon con poderes arbitrarios para gobernarse, como tampoco lo requiere una ciudad bien gobernada. Con ello inaugura una analogía entre la vida animal y la vida política. Examinando algunos textos de él y de filósofos posteriores (Vitoria, Locke, Condillac y Rousseau), se constata que la analogía tiene continuidad y que se complementa con nociones modernas, como la de soberanía e interés. Aplicado por Condillac a los animales, el interés es entendido como una guía que orienta la vida de los animales, y no sólo como un "instinto" conducente a obtener alimentación y reproducción. Asimismo, la capacidad de movimiento de algunos animales requiere algún grado de conciencia de sí, del entorno y de la propia posibilidad de muerte. El conjunto lleva a que es difícil hablar de lo político sin una analogía con la vida animal o viceversa y a que dicha analogía obligaría reconocer derechos a los animales, tal como se constata ya en la jurisprudencia y en algunos textos jurídicos.

Palabras-claVe • Filosofía animal. Biopolítica. Aristóteles. Soberanía. Interés. Filosofía política.

\section{Autonomía y autogobierno animal}

Eidos, una revista orientada a la salud humana, dedicó un número especial a la autonomía del paciente médico, en el contexto más amplio de la bioética, autonomía médica que de inmediato está puesta en relación con conceptos políticos, a pesar de que ello se realice en un contexto ligado a la salud. Para explicar el vínculo entre la autonomía del paciente y la autonomía política, Jesús Conill, uno de los articulistas, describe cómo se concebía para los clásicos griegos dicho concepto:

era una categoría política central. La autonomía fue desde mediados del siglo v a.C. la meta de las ciudades griegas, mediante la que éstas buscaban preservar cierta independencia, especialmente el derecho a poder determinar sus propios asuntos internos. Herodoto entiende la autonomía como libertad (eleutheria) política externa (no depender de un dominio extranjero) e interna (en contraposición al estado de los tiranos). Tucídides usa el concepto de autonomía en su informe sobre el tratado de paz entre los atenienses y los lacedemonios en un 
sentido más restringido, al distinguir la autonomía como propia legislación interna de la soberanía financiera, así como de la propia capacidad de administrar justicia (Conill, 2013, online).

También para Aristóteles la autonomía es un hecho central. En la Política, sostiene que los animales tienen voz, por medio de la cual manifiestan el dolor y el placer, pero no logran significar lo perjudicial o lo conveniente, de forma que carecen de los conceptos de bien y de mal (I, 2, 1253a), lo que no significa que ignoren de forma inmediata lo que los perjudica o beneficia. Con ello, Aristóteles sigue la línea establecida por Platón, según la cual el bien se distingue de los placeres, agregando, sin embargo, una teleología de la naturaleza, pues ese dolor y ese placer poseen un sentido, porque "la naturaleza, como solemos decir, no hace nada en vano" (I, 2, 1253a). Aristóteles reitera esa idea al afirmar que no se debe estudiar la naturaleza de forma abstracta, pues siempre tiene un propósito y que, cuando hay un movimiento animal, éste realiza en función de ese propósito (Parte Anim., I, 1, 6411b). La idea de propósito es también una de las claves de la política aristotélica, cuyo sentido es vivir bien, no en el sentido material, sino el sentido de estar orientado por el bien (Política, I, 2, 1252b). Ese vínculo entre, por un lado, el orden y la finalidad natural y, por otro, el sentido o propósito de la naturaleza, hace especialmente significativa la analogía que establece Aristóteles entre la vida y la política, en especial, la buena política, según afirma en El movimiento de los animales:

la constitución de un animal debe ser considerada como semejante a la de una ciudad bien gobernada. Porque cuando el orden está establecido en una ciudad, no se necesita que esté presente en cada actividad especial un gobernante ( $m o^{-}$ narcon) con poderes arbitrarios (Mov. Anim., 10, 703a).

Otros escritos aristotélicos sobre los animales coinciden en que las sensaciones cumplen con la teleología de la vida y de los seres vivos. En el primer capítulo del segundo libro de Partes de los animales, Aristóteles sostiene que los animales no humanos estarían suficientemente dotados para cumplir con los fines naturales, sobre todo gracias a los movimientos que se necesita para ello. Sin entrar en el debate sobre si Aristóteles anticipa el concepto de función, ${ }^{\mathbf{1}}$ la idea aristotélica de "buen gobierno" no es contradictoria con la concepción contemporánea de un sistema autorregulado donde sus partes cumplen funciones que apuntan a un mismo fin sin que para ello se re- 
quiera ni conocimiento racional de éste ni tampoco un gobierno arbitrario, aunque haya surgido desde adentro. Un sistema autorregulado se identifica también con el ideal de anarquía, no el sentido vulgar que identifica este concepto con algún tipo de desorden o caos, sino en su sentido político. Y, aunque en su significado político y técnico tenga una amplia variedad de acepciones, en todas o casi todas ellas se supone una autoregulación política y social de sus componentes, sin necesidad de que haya un órgano legislador ni tampoco represivo externo al organismo. ${ }^{2}$ A ello se agrega que en ese sistema anárquico se produce un cumplimiento autónomo de funciones por parte de sus miembros, sin que requieran el conocimiento racional de la finalidad que se cumple en cada función, de modo semejante a como un buen trabajador humano no necesariamente conoce ni comprende la finalidad última de su contribución laboral.

El autogobierno funcional de los animales por los animales, sin poderes arbitrarios ni externos, acentúa la analogía política para comprender la autonomía de la vida animal. Sin embargo, el autogobierno animal se da sin consideración al bien y al mal, consideración que es requerida por lo político en varios de los principales sistemas filosóficos, con excepción de la línea que se inaugura con Trasímaco en el diálogo $L a$ república (Platón, 2006, I, 338c) y que continúa con El príncipe (Maquiavelo, 1955 [1582]), quienes, aunque de distinta manera, subordinan la idea de bien, al menos político, a la conveniencia del más fuerte. La ciudad que constituye la vida animal (entendida como unidad analógicamente política) no requiere tampoco de la moralidad, que Aristóteles mantiene reservada a los animales racionales, que pueden producir juicios sobre el bien y el mal, los que incluso pueden ser contrarios a las sensaciones de dolor o placer.

La analogía de la ciudad para explicar la autoregulación de la vida animal depende en gran medida de lo que se entienda por racionalidad y por el carácter abstracto o concreto del juicio moral. Ignacio García Peña entiende la racionalidad aristotélica más bien como comunicación o lenguaje comunicativo:

desde luego, la traducción de logos por lenguaje es la más adecuada. Con todo, es éste quizá uno de los conceptos más polisémicos y que con más dificultad puede transformarse en un solo término castellano. En efecto, la distinción entre lenguaje y voz es esencial para comprender lo que el filósofo nos quiere decir, pues los animales poseen también ciertas herramientas para comunicarse y transmitirse unos a otros las sensaciones de placer y dolor, para advertir sobre peligros y llamar la atención sobre objetos o circunstancias de decisiva importancia (Peña, 2010, p. 300).

2 En la Stanford encyclopeadia of philosophy, el concepto de anarquismo aparece ligado a veintiséis casos, autores y acepciones, la mayoría de los cuales corresponden a las características que atribuimos a ese concepto (University of Stanford, 2013). 
Sin embargo, también aclara que la comunicación humana tiene un objeto propio, que no se restringe a las cosas buenas y malas, al placer o al dolor, sino que

Aristóteles destaca la capacidad humana para comunicar, entre otras cosas, lo justo y lo injusto, y en ello radica precisamente la diferencia específica [entre humanos y animales] (Peña, 2010, p. 300).

La vida de los animales no humanos, que se gobiernan sin gobierno externo, es autosuficiente justamente porque ellos no necesitan un alguien o un algo que ponga orden desde fuera, pero su autogobierno, al menos como lo entiende Aristóteles, debería referirse, entonces, sólo al placer y al dolor. El alma que se requiere para la autosuficiencia de la vida animal está plenamente en los animales; a pesar de no contar con un alma racional o mental, los animales no dan muestras de insuficiencias (Parte Anim., I, 1, 64,1b). Hay una plenitud y autosuficiencia del alma animal, a diferencia del alma de los esclavos, que sólo alcanzarían su plenitud mediante su pertenencia a los griegos y el ser regidos por un amo (Política, I, 5, 1254a). Para Aristóteles, la ciudad y la vida animal tienen todo lo que necesitan para desempeñar su función (Política, I, 2, 1252b, 1253a), lo que contrasta con la vida de los esclavos y de los bárbaros. Los primeros requieren del dominio de los hombres libres para realizar su propio bien, que no es otro que los fines nobles de sus amos: "el que es capaz de prever con la mente es naturalmente jefe y señor por naturaleza, y el que puede ejecutar con su cuerpo esas previsiones es súbdito esclavo por naturaleza; por eso el señor y el esclavo tienen los mismos intereses" (Política, I, 2, 1252a), lo que confirma más adelante: "los bienes que se poseen son un instrumento para la vida, la propiedad en general una multitud de instrumentos, el esclavo una posesión animal y todo subordinado algo así como un instrumento previo a los otros instrumentos" (Política, I, 4, 1253b). Dado que ni los esclavos ni los bárbaros poseen las disposiciones racionales que poseen los griegos, no pueden "prever" (Política, I, 2, 1252b). En consecuencia, el sometimiento de esclavos y bárbaros por los griegos sería conforme a la teleología natural. La vida del esclavo o de los bárbaros requiere el monarcon externo, por no tener un monarcon interno; de ese modo los esclavos entran en el campo de lo político y del dominio legítimo que ejercen los amos y quedan como un bien más al servicio del ocio virtuoso del amo. En efecto, en la Política, Aristóteles sostiene que el esclavo está limitado a la "producción" (poinois) y no a la acción (praxis) ( $\mathrm{I}, 5,1254 \mathrm{a}$ ), correspondiendo esta última a los hombres libres. Esclavos y bárbaros son para Aristóteles una suerte de humanos imperfectos en relación con los griegos libres, que sirven de modelo y a quienes aquellos deben someterse. 
Conviene recordar que la analogía entre el autogobierno de los animales y el buen gobierno de la polis no se reduce a la vida individual, pues todos los seres vivos mantienen relaciones con otros seres vivos, de su especie y de otras. No hay vida humana fuera de la polis en Aristóteles, para quien la vida humana aislada es inconcebible. Por ello, el comportamiento de un miembro aislado artificialmente de la especie humana o de un individuo aislado de una especie animal gregaria no pueden ser tomados como modelo de comportamiento ni político ni social. Cuando Aristóteles habla de vida, entonces, habla también de una interrelación entre distintos individuos y especies, de ahí que la vida se sitúe en un plano que vincula lo individual y lo colectivo, del mismo modo que la ciudad integra también estos dos aspectos.

Aristóteles no requiere introducir aspectos morales en el cumplimiento de los fines de la acción y de la vida puramente animal. El sistema autogobernado animal queda fuera de la exigencia ética, la cual incluso sería exigible, indirectamente, a los bárbaros y a los esclavos, por medio de su sometimiento a los griegos, dotados estos últimos de razón en sentido pleno. Esa ausencia de consideración al bien y al mal en el sistema vital de los animales y su exigencia en el sistema político de los humanos obligan a hablar de analogía y no de igualdad entre cada uno de ellos, sin insinuar que se pueda trasladar directamente un concepto político a la filosofía de la vida, o viceversa. Pero la analogía entre vida y política está bien establecida, como hemos visto, ya en Aristóteles. Así, el buen gobierno de la vida animal queda situado o delimitado por una analogía política, que nunca llega a ser exactamente un hecho político por estar ausente en los animales el juicio necesario para que se pueda dar lo político en sentido estricto, que supone una moralidad o un juicio moral. Los animales no requieren un monarca externo, por llevarlo dentro de sí para cumplir sus fines, es decir, para alcanzar su bien de forma inmediata, sin juicio moral.

Dado que los animales tienen un alma conforme con su propósito y, en consecuencia, gobiernan su cuerpo de acuerdo con ello (De Anima, II, 4, 4,15a-b; Parte Anim., I, 1, 6411b), ¿es legítimo que se hallen sometidos a un orden y a un jefe humano?, ¿cómo se podría justificar el sometimiento en que los humanos mantienen a muchos animales, en especial a aquellos que están dispuestos para el servicio alimenticio, de materiales, sacrificial y de placeres personales? De la filosofía aristotélica se deduce que los animales no requieren de los humanos, ni para vivir ni para alcanzar la perfección que corresponde a su alma. Si los animales no requieren un monarcon, el dominio humano sobre ellos sólo será una situación de hecho, nunca de derecho, a menos que deduzcamos, como hace Aristóteles, la subordinación de los animales a partir de la teoría del alma o psiqué. En Aristóteles, a pesar de la autonomía biológica y ontológica de los animales, quedan subordinados a los animales humanos del mismo modo que lo inferior 
se subordina a lo superior y lo productivo se subordina a los valores políticos, tal como describe en la Moral a Nicómaco (1873). Aunque no sea necesario que los animales se sometan a los humanos de forma análoga a como los esclavos deben someterse a los ciudadanos griegos, la subordinación animal se explica en Aristóteles por la ontología hilemorfista, que supone que las formas inferiores se subordinan a las superiores, en la hipótesis de que la superioridad humana esté dada por la capacidad de juicio racional. No poseyendo los animales capacidad de juicio racional, es decir, de comunicar el bien y el mal, y no sólo el dolor y el placer, no estarían tampoco destinados a un bien más allá de aquél que dicte la sensibilidad inmediata. Tampoco es reconocido por Aristóteles el servicio prestado, exigido o tomado a los animales en favor de los intereses de la comunidad humana. Entonces, ¿cómo entender que siendo Aristóteles un observador tan minucioso de animales y de humanos, no reconozca la dependencia al menos parcial de los ciudadanos griegos respecto de algunos animales domesticados para obtener de ellos alimentos, transporte y otros servicios? Naturalmente hay algún grado de inconsistencia en afirmar, por un lado, la suficiencia de los animales para vivir, similar a la de la ciudad bien gobernada y, por otro, colocar la ciudad animal bajo el dominio completo de la ciudad de los hombres libres. A pesar de la atención aristotélica a los animales, la relación entre éstos y los humanos queda en un plano similar a la relación con los llamados bárbaros, fuera de todo deber y de toda juridicidad, tal cual como la relación con un enemigo no helénico o con una cosa. Aunque Aristóteles sea uno de los filósofos que más haya tratado lo animal, apenas trata el tema de la relación entre los humanos y los animales, lo que consideramos una interpretación política de dicha relación, pues en aspectos fundamentales, ya en el siglo iv a.C., varios animales se encuentran en situación de sometimiento para fines alimenticios, de trabajo y militares similar o inferior que los esclavos. A pesar de no requerir el monarcon con poderes arbitrarios, se da la paradoja de que Aristóteles deja a los animales y a los servicios que proveen sin las protecciones jurídicas ni éticas que sí se tenía con los esclavos.

\section{NUEVAS FORMAS DE AUTONOMÍA ANIMAL}

La manera aristotélica de tratar la relación entre humanos y animales tendrá gran influencia en algunos textos jurídicos y filosóficos posteriores. A mediados del siglo XIII, en las Partidas de Alfonso x, se vuelve a mencionar la autonomía de los animales. En ellas se hace referencia a una tendencia natural de los seres vivos a buscar lo que les conviene, pues "aman y codician naturalmente todas las criaturas del mundo la libertad", pero se aclara que los hombres lo hacen en grado superior "cuando más los hombres que han entendimiento sobre las otras, y mayormente aquellos que son de noble 
corazón" (Reino de España, 1807, partida 4, título xxıı, p. 121). En las Partidas, la suficiencia vital de los animales es descrita como un uso o disfrute de una libertad que les es propia. Ahora bien, en la hora de definir la libertad, queda restringida a los humanos, pues consiste en "poderio que tiene todo hombre naturalmente de hacer lo que quisiere, solo que fuerza ó derecho de ley ó de fuero non gelo [se lo] embargue" (Reino de España, 1807, partida 4, título xxiı, Ley 1, p. 121). Constatamos entonces el ya descrito movimiento de declarar la autonomía a los animales para momentos después considerarla en grado inferior a la autonomía humana. En las Partidas, todos los animales (también los animales humanos) codician la libertad, pero sólo en éstos ese codiciar la libertad tiene un contenido preciso. En el mismo talante se expresará Francisco de Vitoria, quien en su relección De la potestad civil (Vitoria, 1960 [1557]) entiende que el hombre, al que llama "corona del mundo" (\$ 2, p. 153), es superior a los animales "por la razón, por la sabiduría y por la palabra" ( $\$ 3,154)$, de forma que la ontología de la materia y de la forma aristotélica se prolonga hasta la posescolástica. Los hombres necesitan vivir en sociedad para satisfacer sus necesidades y las repúblicas se constituyen,

para que los unos lleven las cargas de los otros, y siendo entre las sociedades la sociedad civil aquella en que con más comodidad los hombres se prestan ayuda, síguese que la sociedad es como si dijéramos una naturalísima comunicación y muy conveniente a la naturaleza (naturalissamam communicationem naturae convenientissimam) (§ 4, p. 156).

La afirmación de que la sociedad es communicatio recuerda la ya citada interpretación del concepto de logos que realiza Ignacio García Peña (cf. p. 263 arriba). Vitoria percibe que la base de la sociedad no es únicamente un intercambio simbólico, como induce a pensar el significado de la palabra castellana "comunicación", sino el llevar las cargas de los otros. Este es, en efecto, el sentido de la palabra "communicationem", que en latín escolástico también tiene el significado de comunidad de intereses (Diccionario, 1971), es decir, un intercambio de servicios que se origina en la naturaleza misma y que Vitoria entiende como fruto de una decisión divina. Los poderes públicos surgen para guardar y proveer a esa comunidad, de forma que,

así como el cuerpo del hombre no se puede conservar en su integralidad si no hubiera alguna fuerza ordenadora que compusiese todos sus miembros, (...) así ocurriría en la ciudad (civitate) si cada uno estuviese solícito de sus propias utilidades y todos descuidasen el bien público (Vitoria, 1960 [1557], § 5, p. 157; énfasis mío). 
Debe notarse la restricción que hace Vitoria en relación con el cuerpo, porque sólo se trata del cuerpo del hombre; es éste el que es gobernado al igual como lo debe ser la ciudad, dejando en silencio cuál es el estatuto del gobierno o del autogobierno del cuerpo de los animales y si pueden servir de modelo para representarse el origen y finalidad del poder político. Sin embargo, dicha restricción no impide que el paralelismo y la analogía entre biología y política sirvan de base, como también en Aristóteles, para comprender y definir el buen gobierno.

Descartes produce una inflexión completa con la teoría del cuerpo-máquina, ${ }^{3}$ propuesta en el Discurso del método, en 1637, y en las Meditaciones metafísicas, de 1641. Sin embargo, la ruptura con la filosofía aristotélica y escolástica producida por Descartes no implica inflexión relativa a la relación entre humanos y animales, pues confirma y acentúa la ausencia de vínculo ético o jurídico en el tratamiento de los animales, tal como ya lo había hecho la tradición que hemos visto. En relación con los animales, la innovación cartesiana no es tanto ética, sino que proviene de dar un nuevo fundamento al planteamiento ya antiguo de la inferioridad de la autonomía animal, rompiendo con la ambigüedad constatada de atribuir una autonomía a los animales para luego negárselas y sustraer a los humanos de vínculos éticos con los animales. Para Descartes, no hay ni ha habido ningún grado de autonomía en los animales, por lo que, si lo seguimos, deberíamos aceptar que el concepto de autonomía queda fuera del campo semántico de la zoología y de la zoofilosofía. Para Descartes, los animales se mueven por mecanismos, al igual que las cosas, colocándolos en el plano de la res extensa y de sus leyes. Entonces ya no es posible plantear ninguna propuesta a partir del monarcon, porque no lo tienen, ni siquiera analógicamente. Tal vez se haya sobrevalorado la influencia cartesiana en la historia de los vínculos entre humanos y animales. Lo que permanece no es tanto su planteamiento mecanicista - que será rápidamente criticado y ridiculizado filosóficamente por Condillac-, sino el hecho de despojar a los humanos de la mantención de vínculos éticos con los animales.

Como hemos dicho, en el Tratado de los animales, de 1755, Condillac critica la teoría cartesiana del cuerpo-máquina, apenas dieciocho años después ser dada a conocer por Descartes. Distanciándose de éste, Condillac coincide con algunos planteamientos clásicos al afirmar el carácter sintiente de los animales, sin siquiera entrar a discutir el planteamiento contrario de Descartes (cf. Condillac, 1796 [1755], p. 436), y le contradice afirmando que los animales tienen una capacidad de representación y asociación de ideas (cf. 1795 [1755], p. 475-6). Por último, Condillac pone el énfasis en la autonomía animal, atribuyéndole facultades similares a las humanas. Más cercano

3 La teoría cartesiana del cuerpo-máquina ha sido expuesta tantas veces que no consideramos pertinente desarrollarla una vez más aquí ante un público especializado. 
de Aristóteles que de Descartes, para el "materialista" Condillac, el desconocimiento de la ley natural por parte de los animales no impide su autoconservación, la que está asegurada por el hecho de que dependería de sensaciones inmediatas de placer y dolor.

Pero los animales [bêtes] cuidan [veillent] por sí mismos de su conservación; se mueven a voluntad y toman lo que les es propio, rechazan, evitan lo que les es contrario; los mismos sentidos que regulan nuestras acciones parecen regular las de ellos (Condillac, 1796 [1755], p. 434).

Y, más adelante,

la felicidad y la desgracia del hombre difiere pues enteramente de la felicidad y de la desgracia de los animales. Felices, cuando tienen sensaciones agradables; desgraciados, cuando las tienen desagradables; sólo hay lo físico bueno o malo para ellos (Condillac, 1796 [1755], p 514).

Ese "físico" se enlaza con la noción de interés, que Condillac atribuye específicamente a los animales y que es el motivo de que entre ellos haya algún grado de aprendizaje y de asociación de ideas.

[El animal] estudia, pero sin tener el propósito de estudiar; no se propone adquirir los conocimientos para hacer de ellos un sistema; está completamente ocupado por los placeres que busca y las penas que evita; sólo le conduce ese interés; avanza sin prever el término donde debe llegar (Condillac, 1796 [1755], p. 474).

Con ello, Condillac descarta que el conocimiento racional de la ley natural o del bien y del mal en cuanto tales sea requisito para el desarrollo autónomo de la vida de los animales, la que se resuelve por las sensaciones y no por los conceptos. Si dicha ley se manifiesta en ellos, si la ley natural está presente en los animales, ello se produce por medio de las sensaciones, sin que se requiera reflexión posterior. Placer y dolor se elevan a una categoría que va más allá de la mera sensibilidad y se convierten en una especie de guía crematística y a la vez política de los animales, porque aquellas sensaciones les permiten obtener lo que requieren para sobrevivir, gregariamente en algunos casos y, además, "tomar lo que les es propio", pero con autonomía. En otras palabras, para Condillac, placer y dolor regulan la vida, de forma similar a esa ciudad que no requiere del monarcon con poderes arbitrarios. La vida animal se constituye en Condillac como un campo autónomo que no necesita de nada para alcanzar algo que 
podríamos llamar su natural equilibrio inestable. Una vez más tenemos el modelo anárquico como representación de la vida animal.

En la perspectiva que hemos analizado en Aristóteles, en las Partidas y en Condillac, la autonomía animal se alcanza por otros medios, ligados a la ley natural, pero en todos esos casos tenemos el esbozo y el vínculo sistemático de conceptos claves de la filosofía política, como son "libertad", "soberanía” y "autonomía”. La argumentación aristotélica relativa a la autonomía animal, como la de Condillac, se emparentan estrechamente con nociones políticas; la explicación sobre la vida no es autónoma de la explicación sobre el gobierno, y viceversa.

\section{EL INTERÉS: MEDIADOR ENTRE LA AUTONOMÍA ANIMAL Y LA SOBERANÍA}

La noción moderna de soberanía puede ser entendida como una versión más profunda y más abiertamente política de la autonomía animal. Esto no significa que el concepto de soberanía haya sido concebido deliberadamente a partir del ya citado modelo de vida animal, sino que, de hecho, incluso por medio de un no darse cuenta de ello, la modernidad continúa inspirándose en él. Con ello, se confirma todavía más la analogía entre monarcon que rige la vida animal y la vida política humana o, dicho de otro modo, la analogía entre la capacidad de velar por sí mismos de los animales y las ideas que explican el origen, legitimidad y finalidad del gobierno humano. Se verifica que también por medio de algunos conceptos modernos es posible atribuir a la vida animal algunas de las características de la soberanía política y que, a la vez, la soberanía política tiene por modelo la supervivencia biológica; todo lo anterior con una sorprendente continuidad, donde la hipótesis cartesiana del cuerpo-máquina no logra anular una línea central de la filosofía política.

En algunos autores modernos, ello se realiza fundamentalmente por la intervención del concepto de "interés", tal como se manifiesta en Locke, Condillac y Rousseau. La distancia de Locke con la filosofía de la vida no impide colocar la noción de interés (interest) como orientadora y guía para la vida. En el Segundo tratado del gobierno civil, el interés es el objetivo de la ley de la razón y, por ello, conduce a los hombres una vez que son adultos, sin requerir un poder paternal o autoritario que los gobierne (cf. Locke, $197^{8}$ [169o], cap. 6). Para Condillac, el interés se identifica con la autonomía de la vida por medio del placer que el animal busca y del dolor que quiere evitar. Esa búsqueda se refleja siempre en una acción, es decir, un movimiento "que sólo el interés dirige" (Condillac, 1796 [1755], p. 474). Se trata de un concepto central, en especial porque aparece después de haber declarado que instinto y apetito no son razones para explicar la actividad de los animales (cf. p. 4422). No hay una definición 
del concepto de instinto en Condillac, ni tampoco del concepto de interés, aunque el contexto en que usa este último muestra que él apunta a explicar el movimiento de la vida animal en oposición a aquél. El interés, para Condillac, no es ni un movimiento mecánico ni tampoco un movimiento reflejo, sino una orientación en la vida de un individuo animal, es decir, posee un sentido. Por una paradoja imprevisible, el sensualismo de Condillac, de orientación más bien monista, contribuye a la idea de que la vida animal es una vida completa, en el sentido de que tiene una plenitud que no la hace requerir de nada externo y que basta para mantener una relación consigo mismo y con el entorno que permita la mantención de los individuos y su reproducción, plenitud que sobrepasa toda crematística.

Un siglo más tarde, Rousseau atribuye al concepto de interés (intérêt) un significado que se suele oponer a la voluntad general y que se asocia a algo contrario al bien común o al deber (cf. Rousseau, 1970 [1762]). Es decir, también para Rousseau, se trata de una fuerza orientada y con sentido, porque, para oponerse a la voluntad general, es necesario que el interés se sitúe en el mismo ámbito semántico de ésta, es decir, en el plano de la autodeterminación y de la libertad. En el Del contrato social afirma:

Pues, primeramente, cada uno, al darse todo entero, la condición es igual para todos, nadie tiene interés en hacerla onerosa a los otros (Rousseau, 1970 [1762], Libro I, p. 360-1).

Así, el deber y el interés obligan igualmente a las dos partes contratantes a ayudarse (...). Ahora, el soberano, estando formado sólo por particulares que lo componen, no tiene ni puede tener interés contrario al suyo (Rousseau, 1970 [1762], p. 363).

Una de las particularidades de la noción de interés en Condillac y en Rousseau consiste en que integra la capacidad de contribuir a la supervivencia colocando los movimientos y decisiones directamente ligados a la vida en el plano de una razón que no es conceptual o al menos no es puramente conceptual. Ninguno de los mencionados filósofos sitúa la autonomía en un ámbito de juicio conceptual sobre el bien y el mal, sino en un componente moral pre-racional, en una voluntad, en una capacidad para decidir ligada a funciones vitales y no a conocimientos. Rousseau vincula entre sí los conceptos de interés y de voluntad quizás con mayor énfasis que otros autores al plantear que la libertad es consecuencia de la naturaleza del hombre, cuya primera ley se vincula con el crecimiento, pues al llegar el niño “a la edad de la razón” está en condiciones de cuidar de sí mismo, pues "siendo él mismo juez de los medios propios para conservarse se convierte por ello en su propio señor" (Rousseau, 1970 [1762], Libro I, p. 352 ). Sólo que esa "edad de la razón” no equivale a una edad en que se alcance juicios 
abstractos, sino más bien una edad en que se puede decidir sobre sí mismo. Ser juez de los propios medios para conservarse significa que el hombre no requiere de intervención externa, que tiene el poder y el juicio autónomos para decidir sobre sí mismo; vale decir que, como en una ciudad bien gobernada, puede prescindir del monarcon con poderes arbitrarios. Ese juicio sobre sí mismo no es una autoreflexión cartesiana, ni una introspección, ni un cálculo, sino algo previo a todo cálculo y a toda introspección, pues es lo que da sentido a cualquier cálculo que permita alcanzar lo que de sí mismo se desea. La teoría de la soberanía, tal como la propone Rousseau en Del contrato social puede ser entendida como un sistema, es decir, como una institución o entidad formada por múltiples elementos cuya relación define el destino de esa institución y de sus miembros. "Suficiencia", "velar por su propia conservación", "soberanía" y "libertad" son conceptos que pertenecen a un mismo campo semántico-político roussoniano y son aspectos de un mismo hecho, que sólo se puede definir mediante el uso del conjunto de dichos conceptos y que conducen a la creación del cuerpo político (cf. Rousseau, 1970 [1762], Libro I, p. 359).

Recordemos que el cuerpo político es, para Rousseau, también una unidad autónoma, que se opone a toda forma de dominio y que tiene vida y voluntad.

Esta persona pública que se forma, así, por unión de todos los otros [miembros] tomaba en otra época el nombre de ciudad, y toma ahora el nombre de república o de cuerpo político, el cual es llamado por sus miembros Estado cuando es pasivo, soberano cuando es activo, potencia comparándolo con sus semejantes. En relación con sus asociados, toman colectivamente el nombre de pueblo y se llaman en particular ciudadanos como participantes en la autoridad soberana y sujetos como sometidos a las leyes del Estado. Pero estos términos se confunden frecuentemente y se toman uno por otro (Rousseau, 1970 [1762], Libro I, p. 360).

Efectivamente, "esos términos se confunden frecuentemente" y más en la noción de "cuerpo político", cuya analogía con la vida adquiere con ello una suerte de consistencia carnal que no tiene la sola noción de "autonomía". No es necesario aceptar la tesis global de la inmunidad o protección de la vida, descrita por Esposito como finalidad de la política, para aceptar su idea de que el cuerpo es el lugar privilegiado de la vida y también donde se concentra la amenaza de muerte, por lo que la metáfora más influyente en el pensar la vida social ha sido el cuerpo (cf. Esposito, 2009, p. 161).

Cuidar de sí mismo no supone, entonces, ni introspección, ni juicios globales, ni tampoco una conceptualización abstracta, sino estar capacitado para velar por el propio interés, lo que se logra al llegar a la edad de la razón en los humanos y por el placer y el dolor, según Condillac, en el caso de los animales. Ello se logra en la inmediatez de 
la voluntad guiada por medio de un logos que versa sobre lo concreto, algo concreto que es más una comunicación en el sentido de Vitoria, es decir, un llevar las cargas los unos de los otros. El interés contribuye al sentido y a la delimitación del concepto de soberanía, entendida no como un actuar arbitrario, azaroso o mecánico, sino como una acción orientada que surge desde el interior de la vida misma a partir del momento en que se alcanza la edad adulta.

El interés es una función de la vida mucho antes que una función económica. Ello se hace aun más claro porque en ninguno de los autores mencionados el interés aparece centrado en una crematística doméstica, comercial o pública, pues se refiere a la cualidad de orientar la vida y apunta a un alcanzar objetivos y a regular el conjunto de las decisiones que los seres vivos, incluyendo los humanos, toman para garantizar su vida, y no para meditar sobre el bien o el mal y menos para definirlo. En el siglo xvII, las raíces filosóficas de la noción de interés no apuntan ni se restringen a lo económico, ya que el concepto concierne a la capacidad de vivir; la noción de interés es más amplia que el incremento de la valorización financiera de los bienes. Es cierto que Locke asocia el interés a la propiedad, pero bajo el concepto de propiedad entiende tanto el fruto del trabajo como la vida, la libertad y la condición (states), cuya conservación constituyen la finalidad de la sociedad política y del gobierno (cf. Locke, 1978 [169o], cap. 9, p. 123).

\section{El movimiento y el Tiempo; EL inTerés y LA Constitugión}

Si los animales (Condillac no precisa cuáles) tienen ideas (cf. 1796 [1755], cap. v), son autosuficientes para decidir sobre su vida y tienen movimiento, deben tener también algún tipo de conciencia de sí mismos. Condillac no reflexiona sobre el hecho de que el movimiento de los animales, ligado a la búsqueda del placer y al evitar el dolor, supone una conciencia de los propios límites o incluso de la posibilidad de la muerte. Aquellos que disponen de movimiento y que además disponen de un sistema nervioso se mantienen en vida gracias a un grado o tipo de conciencia de sí, mayor o menor, según las especies, que permite cierta anticipación sobre el propio destino, porque no hay movimiento sin algún grado de conciencia de ese destino y de su inserción en el tiempo. Naturalmente, no insinuamos que todos los animales tengan esa capacidad, porque el concepto de animal es de una variedad muy amplia, y, como sostiene Derrida, puede haber más proximidad entre los humanos y un mamífero que entre los mamíferos y algunos microorganismos (cf. Derrida, 2006). El desplazarse requiere poseer percepción del espacio, es decir, el desarrollo de algunos sentidos y la capacidad de ejercer algún juicio práctico sobre las percepciones que vinculan a ese individuo con el entor- 
no. Hace falta algún tipo de conciencia en todos los desplazamientos, tanto del entorno como del hecho de que pueden conducir a la destrucción del individuo por caídas, alejamiento de los lugares de protección, del agua u otras consecuencias.

Buscar la vida por el movimiento es exponerse a la muerte; para evitarla, es necesario que el individuo (algunos animales y los humanos) tengan alguna noción práctica de lo que puede acontecerles, y eso muchas veces sin tener placer ni dolor inmediatos. Un animal que se mantiene al borde de un precipicio anticipa lo que sucedería si avanzara; un animal que caza anticipa su movimiento y el de la presa, y ésta el del depredador, lo que supone algún grado o tipo de consciencia de los riesgos y de la posibilidad de perecer en todos ellos. El movimiento de un individuo, animal o humano, sin algún tipo de conciencia de sus límites y riesgos, llevaría a la muerte y, cuanto más complejo y autónomo sea, más amplia es la comprensión. Es más, el darse cuenta del vínculo con una muerte que es una posibilidad de la acción del individuo animal requiere también un vínculo con el tiempo. El animal que se desplaza en el tiempo sabe, no por razonamiento lógico, sino por integración evolutiva y biológica, que está situado en un tiempo que, sin ser un tiempo humano, es un tiempo propio de cada especie y de cada circunstancia, y que tampoco podría ser reducido al tiempo que mide un cronógrafo. Algunos animales concentran o dilatan el tiempo en actitudes de acecho, cortejo, huida etc., porque sus actos están en el tiempo como lo están en el espacio. Simples movimientos animales requieren algún tipo de conciencia de sí, de la relación consigo mismos y con el entorno, y también de la muerte y del tiempo, porque la muerte es uno de los destinos a los que el movimiento puede llevar cuando se traspasan los límites en que ese movimiento es compatible con la vida. Para Jesús Mosterín, los animales, además de información descriptiva del mundo, también procesan información práctica sobre el qué y cómo hacer; "ese tipo de procesamiento o razonamiento desemboca no en una conclusión teórica correcta, sino en una acción adecuada" (Mosterín, 1998, p. 80). El movimiento de algunos animales, al menos de los que disponen de ciertas capacidades orgánicas cerebrales y nerviosas, supone siempre una delicada capacidad de cuidar de sí y de evaluar los riesgos que sobre sí mismo tiene ese movimiento autónomo. Por eso, la afirmación de Condillac, relativa a que los animales tienen ideas y unida a las consecuencias del movimiento, complementa el hecho de que la autonomía de la vida de los animales supone algún grado de conciencia y de autoconciencia, incluyendo la de los propios límites y de la muerte, al menos como posibilidad. ¿Son estos grados de consciencia constituyentes de la idea de soberanía inspirados en el modelo aristotélico de la ciudad suficiente? La ciudad suficiente, sin un monarcon arbitrario, permite comprender la vida como una autoregulación de las inestabilidades y de los intercambios vitales en una situación de conciencia de sí, del en- 
torno y de la muerte como posibilidad. Esta autoregulación, sin embargo, no es resolución de los problemas de la vida, porque resolución implicaría alcanzar una estabilidad que paralizaría los intercambios propios de ella, intercambios que se multiplican y enriquecen en los animales con movimiento, justamente gracias a este, que en mismo lapso permite el contacto con un entorno más variado.

El modelo de la polis, la "suficiencia", la capacidad de velar por la propia conservación, la idea de cuerpo político y otras semejantes son nociones que se aplican a la ciudad, entendida como institución política de los humanos reunidos. Eses conceptos, que tienen origen en el gobierno político, tienen un correlato en la filosofía de la vida animal con la finalidad de comprender la orientación de los movimientos animales, su sentido. Esa analogía de lo político y de la vida se constituye por medio de un conjunto o un sistema de palabras, ninguna de las cuales tiene sentido por sí misma y cuyos contornos son codefinibles y que, como ya planteaba Rousseau, se confunden. Es justamente ese carácter sistémico, quizás algo ambiguo y confuso, tanto por su nomenclatura como por su significado, lo que hace la analogía político-vital más completa, pues no se trata de trasladar una palabra aislada, sino de ver cómo constituyen un conjunto de significados coherentes y paralelos, tanto en el ámbito de la política como en el de la vida y su sentido. Ese conjunto de términos y de facultades o capacidades de la vida, y no una palabra o un hecho aislados, desempeña un papel clave en la fundamentación jurídica de la autonomía individual humana dentro de la ciudad.

Hay, pues, en la modernidad, una analogía entre la noción de llegar a ser cada cual el propio señor y la idea previa que transita desde Aristóteles a Condillac (con el paréntesis cartesiano) de que los animales están capacitados por la misma naturaleza para sobrevivir sin intervención humana. Pero, más importante aún es que en Rousseau el argumento de la supervivencia natural sirve, no para justificar la autonomía animal, sino para justificar la autonomía humana, que se alcanza al llegar a la "edad de la razón”. Esa razón se sitúa en el campo de la comunicación. Esa comunicación no consiste en la opción deliberada (y no natural, como en la filosofía aristotélica o en Vitoria) de vivir gregariamente, porque tal decisión no resulta posible de encontrar, excepto en la ficción filosófico-jurídica del paso del estado natural al social. Lo deliberado y variable en los humanos es la forma de organización de esa comunicación y organización para que unos lleven las cargas de otros, expresado, claro está, mediante la teoría del pacto que se origina en la voluntad. Rousseau se distancia de la idea de sociabilidad natural, pero mantiene la idea más antigua de que la vida social implica una repartición de tareas que no es necesariamente lógico-conceptual. Rousseau asume una perspectiva ontogenética, en la medida en que cada individuo llega a la edad de la razón en un momento espontáneo de la vida individual y sin necesidad de someterse al dominio 
de otros hombres o grupos, ni tampoco de la cultura. La "edad de la razón" no es simplemente un fenómeno político, ni exclusivamente biológico, sino el fundamento de la legitimidad política porque permite deliberar y decidir sobre el pacto social.

La analogía filosófica entre la autonomía de la vida y la autonomía de la ciudad no es sólo un asunto teórico, pues tiene un reflejo directo en algunos textos contractuales de derecho constitucional actual en varios de los países de Occidente. Es decir, la autonomía de la vida y la autonomía de la ciudad se relacionan, no sólo teóricamente, sino también en algunas instituciones contemporáneas, como en la figura jurídico-política de la constitución, eje de muchos estados actuales. El vínculo entre vida y política se produce por medio del interés y de la soberanía, concepto de naturaleza política y vital al mismo tiempo. Tal es el caso de la Constitución Política de la República de Chile, en la que el interés es el fundamento del derecho a participar en actos jurídicos en la República (cf. República de Chile, 2005). En dicha constitución, el interés es entendido de manera cercana a como hemos visto se entiende en Locke y en Rousseau, es decir, como una orientación de la razón práctica que guía a los hombres una vez que son adultos, sin requerir un poder paternal o autoritario para intervenir en los actos jurídicos de la república. En el artículo 8, el "interés nacional" es fundamento para que los agentes y poderes públicos puedan actuar sin dar publicidad a sus actos; en el mismo lugar, describe el "conflicto de interés" que puede resultar en el actuar de un funcionario; en el artículo 14, se describe el "interés público o privado" como fundamento del "derecho de presentar peticiones a la autoridad (...) sin otra limitación que la de proceder en términos respetuosos y convenientes"; en el artículo 23, el interés nacional legitima la restricción a la adquisición de bienes; en el artículo 24, se sostiene que "nadie puede, en caso alguno, ser privado de su propiedad, del bien sobre que recae o de alguno de los atributos o facultades esenciales del dominio, sino en virtud de ley general o especial que autorice la expropiación por causa de utilidad pública o de interés nacional" etc.

Si el interés aparece como fundamento de la capacidad de actuar, la soberanía aparece como el ejercicio mismo de la decisión sobre la propia vida, en especial, sobre la vida de la ciudad. El artículo 5 sostiene que "la soberanía reside esencialmente en la Nación. Su ejercicio se realiza por el pueblo a través del plebiscito y de elecciones periódicas y, también, por las autoridades que esta Constitución establece"; y en el 22, que la soberanía debe ser defendida: "los chilenos tienen el deber fundamental de honrar a la patria, de defender su soberanía y de contribuir a preservar la seguridad nacional y los valores esenciales de la tradición chilenos."

En el caso de la República francesa, hay numerosas referencias a las poblaciones y asambleas interesadas (intéressées) y a los intereses (intérêts) nacionales. "Interessadas" se refiere a cada caso en que una población o una asamblea legislativa, que ejerce 
la soberanía, se vea afectada por alguna decisión o deba legalmente pronunciarse sobre ella. Por eso, podemos entender que es el interés lo que permite o incluso obliga a poner en práctica la soberanía o decisión por sí mismo, la cual, según el artículo tercero, "pertenece al pueblo, que la ejerce por medio de sus representantes o por vía de referéndum" (Assemblée Nationale, 1958), todo ello según el propósito enunciado en el artículo segundo de la Declaración de derechos humanos y del ciudadano, de 1789 .

La finalidad de toda asociación política es la conservación de los derechos naturales e imprescriptibles del Hombre. Estos derechos son la libertad, la seguridad y la resistencia a la opresión (Assemblée Nationale, 1789, artículo II).

En los textos jurídicos recién citados, se constata que los conceptos de interés, soberanía y libertad forman un sistema autoreferente, con fronteras variables, pero siempre relacionadas. El sentido de cada uno de esos conceptos codefine al otro, cumpliéndose lo que afirmaba Rousseau de que se confunden, no en el sentido de que estén mal definidos, sino de que las definiciones se superponen y carecen de sentido fuera del sistema. Interés y soberanía son dos de las principales formas políticas del velar por sí mismo en la ciudad contemporánea de los humanos. La analogía de la filosofía de la vida y del derecho constitucional no es del todo sorprendente si se considera que una constitución política en una sociedad humana debe resolver, antes que nada, un problema de sobrevivencia, común en aspectos centrales a humanos y animales. La organización de las relaciones entre sus miembros es el primer asunto que cualquier especie animal gregaria debe resolver; allí se juega la vida, pero también la libertad. En el caso de los humanos, las democracias representativas se basan sobre la hipótesis filosófica, jurídica y política de que el primer acto que realiza una república es darse una constitución, es decir, las reglas fundamentales de convivencia y organización de las relaciones entre sus miembros, y que la constitución precede a la designación de representantes o jefes.

La analogía política para comprender la vida es multifacética y transita por una diversidad de regímenes políticos y épocas filosóficas, pero en todas las que hemos visto se detecta que la analogía es bidireccional y que no hay prioridad de un miembro de ella sobre el otro. La analogía constituye un todo que podemos llamar biopolítico en el sentido de que algunos conceptos clave son comunes, en especial, los que tienen que ver con el gobierno y autogobierno, y en el sentido de que la libertad y la vida, aunque distintas, forman parte del objeto central que debe resolver la política. Esto no es sólo una deriva exclusivamente contemporánea, como tampoco lo es el hecho de que la política tenga por finalidad la protección, por un lado, de la vida y, por otro, de la vida de lo político. El traspaso analógico de algunos conceptos de la filosofía de vida a la filoso- 
fía política es uno de los componentes esenciales de la política y del pensamiento político en Occidente. Con ello, se abre también una paradoja: si el interés o la soberanía son fundamento de la acción jurídica y de la capacidad de decidir colectivamente en asuntos políticos en beneficio humano, aceptar que los animales o al menos algunos animales tengan interés en su vida debiera, también, llevar a admitir que son sujetos de al menos algún tipo de derecho y que ese derecho se define en relación con el cuidado que se deben a sí mismos o, en el caso de que estén desprovistos de deberes, del cuidado que simplemente se tienen a sí mismos, y no en relación con el beneficio que los humanos puedan obtener de los animales.

La noción de interés utilizada por Condillac o, antes y de manera explícita, la afirmación ya vista de que la constitución de un animal debe ser considerada como semejante a la de una ciudad bien gobernada refuerza la idea de que el velar por sí mismos de los animales no consiste sólo proveerse de alimento y cobijo. La vida de algunos animales, si es suficiente como la ciudad aristotélica, no se agota ni en la subsistencia, ni en la reproducción, ni en la disposición de ciertas habilidades más o menos comparables con las humanas, ni tampoco puede el animal ser entendido como el esclavo aristotélico que no es dueño de sí mismo. Los animales no son un humano insuficientemente desarrollado o carente de algunos derechos o capacidades. La noción de velar por sí mismo y de monarcon interior dan cuenta de una autonomía vital y existencial, y no sólo del hecho de disponer de alguna sensibilidad o inteligencia distinta de la humana. Por ello mismo podemos preguntarnos si corresponde a la vida animal un tipo de existencia propia, es decir, si en paralelo a las características políticas de los animales, poseen ellos también un estatuto ontológico propio. Sobre esos aspectos, pero con una visión contemporánea, resulta pertinente recordar el concepto acuñado por Merleau-Ponty de que los animales, según cada especie, serían o dispondrían de una existencia diferente de la humana, que no puede reducirse a una existencia comparativamente inferior a ésta (cf. Merleau-Ponty, 1977, p. 177). Detrás de esa idea está el doble hecho de que la vida no es una simple vida, es decir, no es la sustitución de un mecanicismo cartesiano por un biologismo que, en el fondo, escondería otra forma de mecanicismo, y que la vida animal, por su autonomía, no puede ser valorada teniendo como patrón la humana.

Una pregunta que se deduce naturalmente es cuáles serían las características de los seres que están dotados de interés y, en especial, cuáles pueden ser sujetos de derecho. En el mundo occidental se suele entender que sujetos de derecho son las llamadas personas naturales y las personas jurídicas o morales (el Estado, asociaciones, empresas etc.). Pero estas últimas no fueron aceptadas como sujeto de derecho sin dificultad. 
En los sistemas legislativos actuales es sujeto de derecho todo ente sea humano o no, que es titular de derechos y obligaciones; aunque tal expresión no es de origen romano, en efecto, no aparece en la obra de los juristas, ni en las constituciones imperiales, ni en la compilación justineana (...). La noción de "persona no humana" es el producto de un proceso mental mediante el cual alguien atribuyó a los entes ideales la "personificación jurídica". La expresión "persona jurídica" es extraña a las fuentes romanas donde se utilizaron términos como "collegium", “corpora", "universitas", "sodalitas", "societas" (...). El concepto sobre las personas jurídicas en Roma dio lugar a polémicas entre los intérpretes (Mariani, 2005, online).

Una evolución similar a la ocurrida respecto de la noción de persona jurídica en las doctrinas jurídicas comúnmente aceptadas en Occidente puede darse en relación con algunos animales. Aceptar que algunos animales puedan ser sujetos de derecho en virtud de sus intereses o en virtud de que su vida no requiera de un monarcon arbitrario es una concepción que se debate filosófica y jurídicamente, sin perjuicio de que ya se pueda constatar una inflexión en la jurisprudencia, que en algunos casos tiende a la "personificación” de algunos aspectos de la naturaleza. Según se deduce de algunos veredictos de cortes europeas y también de algunos textos constitucionales de ese continente, hay aspectos de la vida animal que ya encuentran aceptación en la jurisprudencia, como son "su capacidad de sufrir, la afección que les tenemos y que nos tienen, y el tomar en cuenta su mundo mental, es decir, de una forma propia de subjetividad" (Hermitte, 2011, p. 177). Es notable la decisión de la corte de apelaciones de Reims que, en el caso $06-8285$, de 2007, califica de maltrato animal "los actos de penetración sexual" en un momento en que el animal "no podía ejercer ninguna voluntad" (apud Hermitte, 2011, p. 180-1);4 los artículos 79 y 80 de la Constitutución de la Confederación Suiza ([s.d.]) establecen la obligación constitucional de proteger los animales y la naturaleza; y el artículo 71 de la Constitución de la República del Ecuador se titula "Derechos de la naturaleza", y declara que

la naturaleza o Pacha Mama, donde se reproduce y realiza la vida, tiene derecho a que se respete integralmente su existencia y el mantenimiento y regeneración de sus ciclos vitales, estructura, funciones y procesos evolutivos. Toda persona, comunidad, pueblo o nacionalidad podrá exigir a la autoridad pública el cumplimiento de los derechos de la naturaleza (República del Ecuador, 2011).

4 La misma corte decide, el 11 de marzo de 2008, en contra del propietario de un elefante a fin de que éste disponga de condiciones de vida adecuadas a su "distracción" y se eviten "alteraciones de su comportamiento" (Hermitte, 2011, p 177-8). 


\section{Conclusion: ¿Existen los animales?}

La autonomía no arbitraria ni tiránica de la vida animal puede ser considerada no sólo como un hecho biológico, sino también como una forma de ser. En un sentido no contradictorio con el nuestro, Florence Burgat desarrolla justamente una fenomenología de esa existencia en el supuesto de que los animales constituyen un campo ontológico propio. Para Burgat, el examen del estatuto ontológico de los animales merecería una consideración a la cual la filosofía de la existencia no hace justicia, ni en su versión heideggeriana, ni tampoco en la sartriana (cf. Burgat, 2012). En efecto, en la analítica del Dasein, concepto que, sin coincidir con lo humano no es del todo distinto de ello, Heidegger describe los animales como "carentes de mundo" (Heidegger, 1992, §45, p. 273), en contraposición al Dasein, que sería “configurador" de mundo ( $\$ 46$, p. 284). En resumen, para Heidegger, el animal tiene "menos" mundo, menos como opuesto a riqueza (Reichtum) y como la pobreza (Armut) es menos frente a lo más ( $\$ 46$, p. 284). Heidegger plantea que el mundo de los animales está restringido a determinado ámbito y que esa restricción es también una dificultad para penetrar el entorno con el que, sin embargo, están en contacto y que es accesible (zugänglich), es decir, los animales carecerían para Heidegger de la conciencia de sí (vinculado al entorno o al mismo individuo) que nosotros, en ese texto, tomando distancia del pensador alemán, hemos considerado consubstancial a al menos algunas de las especies que se mueven. Sartre, por su lado, en la segunda parte de El ser y la nada, no dedica una reflexión específica a los animales, quedando en su obra comprendidos en el vasto campo del en-sí, de las cosas, de aquello que carece de consciencia de sí, y desprovisto del conjunto de estructuras del para-sí o consciencia, conciencia esa que abarca tres conjuntos: las estructuras inmediatas, la temporalidad y la trascendencia (cf. Sartre, 1980). A esos planteamientos de Heidegger y de Sartre, Burgat, inspirándose en Merleau-Ponty, opone una vida provista de una existencia diferente, con historia, conciencia y algún tipo de autoconciencia, también de la muerte, aunque no necesariamente de una conciencia conceptual. Consideramos que ese planteamiento es compatible con el nuestro, en sentido de que los animales no requieren de un monarcon arbitrario y externo, debido a que ya tienen un monarcon propio, y que en los animales provistos de movimiento existe algún grado de consciencia de sí, del entorno y de las consecuencias que se deducen del movimiento, incluyendo la muerte, según hemos descrito. Nada indica, como pretende Heidegger, que la conciencia de la muerte sea una exclusividad del Dasein, a menos que extendamos el Dasein a los animales, lo que Heidegger no hace. Por ello, Burgat sostiene que 
hablaremos de existencia cada vez que un ser vivo es, no sólo un centro a partir del cual se organizan sus relaciones con el entorno, sino incluso el sujeto de sus experiencias o que ellas son vividas en primera persona (Burgat, 2012, p. 353).

Esta definición no es idéntica de la autonomía que hemos detectado, porque supone el concepto de "sujeto de experiencia" entendido de manera más individual que lo que hemos propuesto en las líneas anteriores. Con todo, y sin entrar en el detalle de la exégesis que hace Burgat, la idea de que los animales dispongan de una existencia lleva a definir un campo ontológico que corresponde a una vida autónoma y que se autogobierna, cuya hermenéutica no debiera llevarse a cabo por comparación con el patrón humano, sino con un patrón propio de cada especie animal. La existencia de los animales puede ser considerada un aspecto ontológico del hecho etológico y político de que velen por sí mismos, velar que no puede tampoco ser evaluado por comparación con la forma en que lo hacen los humanos: por ello, hemos sostenido que hablar de gobierno de la vida y de gobierno político es una analogía, quizás inevitable, pero no más que una analogía entre dos mundos, el animal y el humano, que son distintos. En otras palabras, la analogía entre la ciudad animal y la ciudad humana no debe ser entendida exactamente como una comparación y menos como un establecer a una como patrón de la otra. Con la autonomía que se deduce del interés propio de los animales se establece también la autonomía de la valoración de cada sistema de autoconservación, equivalente biopolítico del hecho de que los animales sean una existencia diferente y que dispongan de un monarcon propio y nada arbitrario.

No parece posible privarse de la analogía política para hablar de la vida y del movimiento animal, porque lo político - lo relacionado con el gobierno y autogobierno humano - es inseparable de la vida. La autonomía dada a los animales por lo que en la filosofía clásica y escolástica es llamado la ley natural permite que no se requiera una ruptura con la naturaleza para aceptar la autonomía y la capacidad de decisión sobre sí mismo. El estatuto de los animales, vital, existencial y político, debería quedar delimitado como algo distinto y autónomo del que posean los ciudadanos y los esclavos, y esa autonomía la podemos caracterizar como soberanía o capacidad de buscar el interés propio.

No se requiere de una institucionalización política expresa y deliberada para detectar algunos de los rasgos que desempeñan una función en la vida animal análogo a lo político: la autonomía está dada ya en la naturaleza y por la naturaleza. No es de ningún modo necesario exigir una "autonomía" de los animales o de los humanos respecto de la naturaleza para concebir la autonomía de la acción y de la vida, y de ninguna forma se puede entender tampoco que el interés, en tanto guía de la acción, requiera 
una "independencia" de la naturaleza. El interés y la soberanía, humana y animal, se ejercen en la naturaleza y muchas veces por medio de ella o con ella; no son conceptos que podamos atribuir exclusivamente a eso que se llama "civilización". No existe una voluntad fuera del interés de la vida y la noción de interés - que es una orientación en la vida y no un cálculo económico - conduce a un nivel de autonomía de la vida animal respecto de la vida humana que debiera, dentro de esa misma tradición de filosofía política, fundamentar los vínculos éticos y políticos entre humanos y animales.A

Hernán NeIRA

Universidad de Santiago de Chile.

hernan.neira@usach.cl

Politics and animal life: the analogy of the good government

\begin{abstract}
Aristote maintains that, in order to govern themselves, animals need neither a monarcon with arbitrary powers, nor a well governed city. With this assessment he establishes an analogy between animal life and political life. Following analysis of some of his and later philosophers' (Vitoria, Locke, Condillac, and Rousseau) texts, we can affirm that this analogy has displayed continuity and that it is complemented with some modern concepts, such as those of sovereignty and interest. Applied by Condillac to animals, the concept of interest is understood as a guide that orientates their life, and not only as an "instinct" conducive to obtaining food and enabling reproduction. Likewise, the capacity of movement of some animals requires a certain degree of consciousness of self, of the environment and of the possibility of their own death. The ensemble shows that it is hard to talk about the political without an analogy with the animal life, and vice versa; and that the analogy would support the obligation to recognize rights of animals, as already some courts have decided and as can be found in some legal texts.
\end{abstract}

KEYwords • Animal philosophy. Biopolitics. Aristotle. Sovereignty. Interest. Political philosophy.

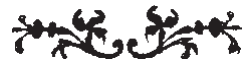




\section{REFERENGIAS BIBLIOGRÁFIGAS}

ARIstóteles. Moral a Nicómaco, 187̧3. Disponible en: <www.filosofia.org: http://www.filosofia.org/cla/ ari/azco1.htm\#pri>. Acceso en: 10 ago. 2013.

. On the soul. Traducción W. S. Hett. Cambridge: Harvard University Press, 1957. (De Anima)

. Política. Traducción J. M. Araújo. Madrid: Centro de Estudios Políticos y Constitucionales, 2005.

(Política)

. Part of animals. Traducción A. L. Peck \& E. S. Forster. Cambridge: Harvard University Press, 2006. (Parte Anim.)

. Moviment of animals. Traducción A. L. Peck \& E. S. Forster. Cambridge: Harvard University Press, 2006. (Mov. Anim.)

Assemblée Nationale. Constitución de la República Francesa, del 4 de octubre de 1958. Disponible en: <http:/ /www.assemblee-nationale.fr/connaissance/constitution.asp>. Acceso en: 05 ago. 2013.

Déclaration des droits de l'homme et du citoyen, de 1789. Disponible en: <http://www.assembleenationale.fr/connaissance/constitution.asp>. Acceso en: 05 ago. 2013.

Blaghair, A. (Ed.). Oeuvres choisies de Condillac. Paris: [s.n.], 1796. 2v.

Burgat, F. Une autre existence. París: Fayard, 2012.

CEGGhi, M. et al. El ¿delito? de Aristóteles. Revista Chilena de Historia Natural, 74, p. 707-14, 2001.

Condillac, E. B. Traité des animaux. In: Blaghair, A. (Ed.). Oeuvres choisies de Condillac. París: [s.n.], 1796 [1755].v. 2. Disponible en: <http://www.ac-nancy-metz.fr/enseign/philo/textesph/TRAITE_DES_ ANIMAUX_Originel.rtf $>$. Acceso en: $0_{5}$ ago. 2013.

Confederación Suiza. Constitution, [s.d.]. Disponible en: <http://www.parlament.ch/f/ wissen/libundesverfassung/Pages/default.aspx>. Accesso en: $0_{5}$ ago. 2013.

Conill, J. La invención de la autonomía. Revista de la Fundación de Ciencias de la Salud, febrero, 2013. Disponible en: 〈http://revistaeidon.es/index.php/ficha/3/La-Invencion-de-la-Autonomia-1/〉. Accesso en: 27 de jul. 2013.

Derrida, J. L'animal que donc je suis. Paris: Galilée, 2006.

Diccionario Ilustrado Latino-Español. Barcelona: Bibliograph, 1971.

Esposito, R. Inmunitas. Protección y negación de la vida. Buenos Aires: Amorrortu, 2009.

Gagnebin, B. \& Raymon, M. (Ed.). Jean-Jacques Rousseau. Oeuvres complètes. Paris: Gallimard, 1970. 5v. (Collection Bibliothèque de la Pléiade, $15^{3}$ ).

Heidegger, M. Grundbegriffe der Metaphysik. Welt-Endlichkeit-Eisemkeit. Frankfurt am Main: Vittorio Klosterman, 1992.

Hermitte, M.-A. La nature, sujet de droit? Annales. Histoire, Sciences Sociales, 1, p. 173-212, 2011.

Locke, J. Two treatises of government. London: Evryman's Library, 1978 [169o].

Maquiavelo, N. El príncipe. Traducción L. Arocena. Madrid: Universidad de Puerto Rico/Revista de Occidente, 1955 [1582].

Mariani, M. A. G. Las personas jurídicas en el derecho romano, 2005. Disponible en: <https://sites. google.com/site/derechoromanoucc/xvii-encuentro-nacional-de-profes ores-de-derecho-romanode-la-republica-argentina-homenaje-al-dr-luis-rodolfo-arguello-ı/MariaAntonieta Gui\%C3\% BıazuMariani.pdf? attredirects $=\circ \& d=1>$. Acceso en: $\circ 8$ nov. 2013.

Merlead-Ponty, M. La structure du comportement. Paris: Presses Universitaires de France, 1977.

Mosterín, J. Que vivan los animales. Madrid: Debate, 1998.

PEÑA, I. G. Animal racional: breve historia de una definición. Anales del Seminario de Historia de la Filosofía, 27, p. 295-313, 2010. 
Platón. La república. Traducción J. M. Fernández-Galiano. Madrid: Centro de Estudios Políticos y Constitucionales, 2006.

Reino de España. Las siete partidas del rey don Alfonso x, el sabio. Madrid: Imprenta Real, 1807 .

República de Chile. Constitutución Política (1980), 2005. Disponible en: 〈http://bcn.cl/4ram en: 13 nov. 2012.

República del Ecuador. Constitución de la República del Ecuador, 2011. Disponible en: <http://issuu.com/ direccion.comunicacion/docs/constitucion_reformada>. Acceso en: 8 nov. 2013.

Rousseau, J. J. Du contrat social ou principes du droit politique. In:. Gagnebin, B. \& Raymon, M. (Ed.). Jean-Jacques Rousseau. Oeuvres complètes. Paris: Gallimard, 1970 [1762].v. 3, p. 347-470. (Collection Bibliothèque de la Pléiade, $15^{3}$ ).

SARTre, J-P. L'être et le néant. Paris: Gallimard, 1980.

University of Stanford. Anarchism. Stanford encyclopedia of philosophy. Disponible en: <http://plato. stanford.edu/search/searcher.py? page=3\&query=anarchism $>$. Accesso en: 23 oct. 2013.

Urdanoz, T. (Ed.). Obras de Francisco de Vitoria. Madrid: Biblioteca de Autores Cristianos, 1960.

Vitoria, F. de. De la potestad civil. In: Urdanoz, T. (Ed.). Obras de Francisco de Vitoria. Madrid: Biblioteca de Autores Cristianos, 1960 [1557].

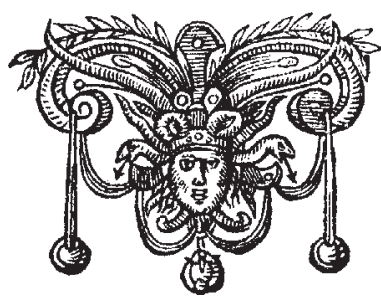

